\title{
Polymorphism $-2604 \mathrm{G}>\mathrm{A}$ variants in TLR4 promoter are associated with different gene expression level in peripheral blood of atherosclerotic patients
}

\author{
Silvia Ferronato ${ }^{1,5}$, Macarena Gomez-Lira ${ }^{1,5}$, Marta Menegazzi ${ }^{2}$, Erica Diani ${ }^{1}$, Silvia Olivato ${ }^{3}$, \\ Marianna Sartori ${ }^{1}$, Alberto Scuro ${ }^{4}$, Giovanni Malerba ${ }^{1}$, Pier Franco Pignatti ${ }^{1}$, Maria Grazia Romanelli ${ }^{1}$ \\ and Sara Mazzucco ${ }^{3}$
}

Toll-like receptor-4 (TLR4) is a primary receptor of the innate immune reaction and compelling evidence demonstrates its involvement in the pathogenesis of atherosclerosis and stroke. TLR4 is constitutively expressed on monocytes and endothelial cells; it is highly expressed in atherosclerotic plaques and in peripheral blood of patients after ischemic stroke. Polymorphisms in the promoter region that alter the transcriptional regulation of this gene may represent genetic risk factors involved in the predisposition to atherosclerotic disease. In this study we investigated the effect on TLR4 gene expression of three polymorphisms in the upstream regulatory region at positions $-1607 \mathrm{~T}>\mathrm{C} / \mathrm{rs} 10759932,-2026 \mathrm{~A}>\mathrm{G} / \mathrm{rs} 1927914$ and $-2604 \mathrm{G}>\mathrm{A} / \mathrm{rs} 10759931$ in peripheral blood of atherosclerotic patients. RNA from individuals homozygous for the $-2604 \mathrm{~A}$ allele showed a lower expression of the gene when compared to patients carrying the counterparts GG $+\mathrm{GA}$. Electrophoretic mobility shift assays showed differences in the electrophoretic mobility of the DNA-nuclear protein complexes formed by the G $>$ A variants, suggesting that the two alleles differ in their binding affinity to transcriptional factors.

Journal of Human Genetics (2013) 58, 812-814; doi:10.1038/jhg.2013.98; published online 10 October 2013

Keywords: atherosclerosis; peripheral blood; TLR4 gene expression; TLR4 polymorphisms

\section{INTRODUCTION}

Stroke is the third cause of death and the first cause of permanent disability in developed countries. Up to $15 \%$ of ischemic events are associated with atherosclerotic carotid stenosis. ${ }^{1}$ Toll-like receptor-4 (TLR4), the primary receptor of the innate immune system, is crucial for endotoxin signaling and is a limiting factor for the innate response to bacterial liposaccharide (LPS). ${ }^{2}$ Besides LPS various endogenous ligands for TLR4 have been identified and some have been proposed to function in the process of atherogenesis. ${ }^{3-5}$ TLR4 is expressed in circulating monocytes, ${ }^{6}$ and in a number of different cell types present in the plaques of atherosclerotic patients. ${ }^{7}$ There is evidence that overexpression of this gene is involved in initiation and progression of atherosclerosis. ${ }^{8}$ Activation of TLR4 initiates an intracellular signaling cascade, leading to the activation of nuclear factor (NF)- $\mathrm{KB}$ transcriptional factor, which promotes the induction of a proinflammatory response, including the release of antimicrobial peptides, inflammatory cytokines and chemokines. ${ }^{9}$ Genomic variations that alter TLR4 gene expression may represent genetic risk factors involved in the predisposition to atherosclerosis and ischemic events. ${ }^{10}$ The aim of this study is to investigate if polymorphisms in the TLR4 gene promoter region may influence gene expression in peripheral blood of atherosclerotic patients.

\section{RESULTS AND DISCUSSION}

Consecutive patients undergoing carotid endarterectomy at Verona University Hospital were enrolled, with either a recently symptomatic or an asymptomatic internal carotid artery (ICA) stenosis, as described elswhere. ${ }^{11}$ Controls were individuals presenting no sign of atherosclerotic plaques at ecodoppler examination. DNA and total RNA were extracted from peripheral blood samples. ICA stenosis degree was stratified into $50-69 \%, 70-80 \%$ and $>80 \%$. Clinical severity of stroke was rated through the National Institute of Health Stroke Scale (NIHSS). ${ }^{12}$ Functional polymorphisms $-1607 \mathrm{~T}>\mathrm{C}$, $-2026 \mathrm{~A}>\mathrm{G}$ and $-2604 \mathrm{G}>\mathrm{A}^{13}$ were genotyped by PCR-restriction fragment length polymorphism (Supplementary Table 2), and gene expression was performed by Real-time PCR as described ${ }^{11}$ (Supplementary Table 3). By in silico analysis, other single-nucleotide polymorphisms present in the region do not alter transcription-

${ }^{1}$ Section of Biology and Genetics, Department of Life and Reproduction Sciences, University of Verona, Verona, Italy; ${ }^{2}$ Section of Biological Chemistry, Department of Life and Reproduction Sciences, University of Verona, Verona, Italy; ${ }^{3}$ Section of Neurology, Department of Neurological and Movement Sciences, University of Verona, Verona, Italy and ${ }^{4}$ Department of Vascular Surgery, University of Verona, Verona, Italy

${ }^{5}$ Silvia Ferronato and Macarena Gomez Lira are both first authors.

Correspondence: Dr M Gomez-Lira, Section of Biology and Genetics, Department of Life and Reproduction Sciences, University of Verona, Strada Le Grazie 8, Verona 37134, Italy.

E-mail: macarena.gomezlira@univr.it

Received 19 November 2012; revised 15 July 2013; accepted 31 August 2013; published online 10 October 2013 
binding sites or are in strong linkage disequilibrium with the selected ones. ${ }^{13}$ Gene expression differences between genotypes of polymorphisms were assessed by analysis of variance test. Dominant and recessive models were tested by the Student's $t$-test. Single analysis was adjusted for multiple tests $(P<0.02)$. Fisher's exact test showed no significant difference between symptomatic and asymptomatic patients for clinical variables (except for sex; Supplementary Table 1). Allele frequencies and genotype distribution are shown in Supplementary Table 4.

TLR4 expression was significantly higher in symptomatic patients compared with asymptomatic and controls. No difference between asymptomatic and controls was observed (Supplementary Figure 1).

TLR4 gene expression showed no correlation with age or NHISS (data not shown).

A trend of association of TLR4 gene expression with stenosis degree was observed in symptomatic patients $(P=0.05$, Figure 1$)$. The most severe grade of stenosis showed the highest TLR4 gene expression, suggesting that TLR4 expression could represent a marker of disease severity in this group of patients.

Gene expression showed no significant differences between the different genotypes of variants $1607 \mathrm{~T}>\mathrm{C}$ and $-2026 \mathrm{~A}>\mathrm{G}$ (data not shown). Polymorphism $-2604 \mathrm{G}>\mathrm{A}$ showed a lower level of TLR4 expression of the genotype $-2604 \mathrm{AA}(0.86 \pm 0.58$ (AA) vs $1.58 \pm 1.9$ $(\mathrm{GA}+\mathrm{GG}), P<0.02$; Figure 2$)$. This difference was also observed among groups when patients were divided into symptomatic, asymptomatic and control group. Consistently, linear regression analysis demonstrated that this effect was independent from disease status, indicating that both disease and genotype may influence TLR4 expression.

The lower gene expression observed in individuals carrying the $-2604 \mathrm{AA}$ genotype is consistent with previous studies, ${ }^{14}$ in which vector constructs containing the $-2604 \mathrm{~A}$ variant, which creates a putative GATA-2 transcription-binding site, showed lower promoter activity when transfected into A498 renal carcinoma cells. To determine whether this polymorphism alters the transcription-binding site for GATA-2, electrophoretic mobility shift assay (EMSA) was performed as described. ${ }^{14}$ In brief, we used radiolabeled oligonucleotide probes containing either $-2604 \mathrm{G}$ or $-2604 \mathrm{~A}$ probes (Figure 3). On incubation of the probe $-2604 \mathrm{~A}$ with cell nuclear extracts, two distinct prevalent complexes (indicated as $\mathrm{C} 1$ and $\mathrm{C} 2$, in Figure 3) were revealed. The specificity of the binding reaction was confirmed by full competition of the non-labeled GATA oligonucleotides compared to the almost absence competition of nonlabeled NF- $\kappa \mathrm{B}$ consensus binding site oligonucleotides. In the presence of excess of the non-labeled $-2604 \mathrm{~A}$ fragment, the complexes $\mathrm{C} 1$ and $\mathrm{C} 2$ were competed away too, demonstrating the specificity for the probe. Compared to A allele, the 2604G probe showed a different electrophoretic mobility of the $\mathrm{C} 1$ complex (Figure 3), indicating that the $-2604 \mathrm{G}>\mathrm{A}$ polymorphism can affect the binding affinity of the TLR4 promoter to transcription factors. The pattern of complexes resulted similar to that obtained by a consensus GATA sequence, suggesting that members of the GATA family participate in the complex. The supershift analyses in presence of the antibody directed to GATA-2 transcription factor (Santa Cruz Biotechnology, Santa Cruz, CA, USA) failed to detect a mobility shift
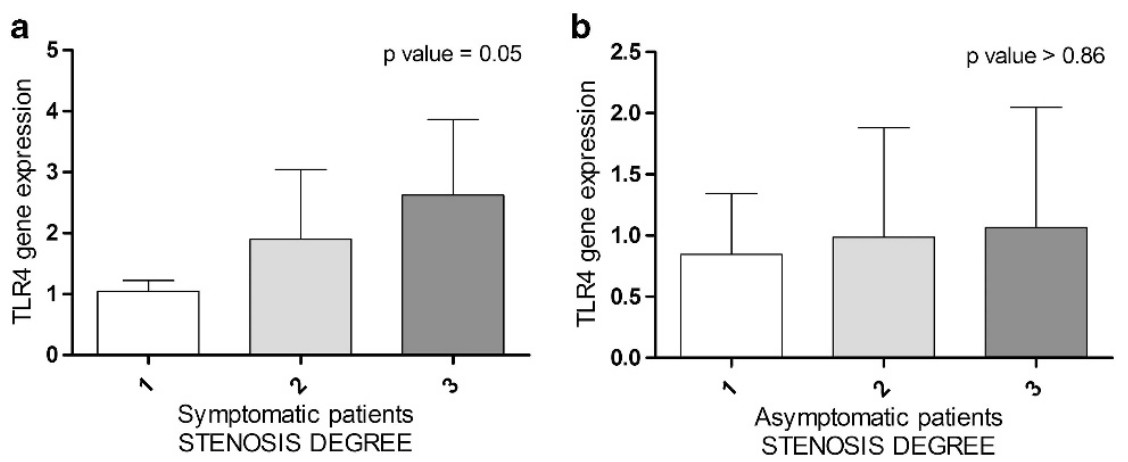

Figure 1 TLR4 gene expression in relation to stenosis degrees in symptomatic (a) and in asymptomatic patients (b). (1) ICA stenosis degree of 50-69\%, (2) $70-80 \%$ and (3) $>80 \%$. Bars indicate mean values for each group. $P$-value is indicated in the graph.
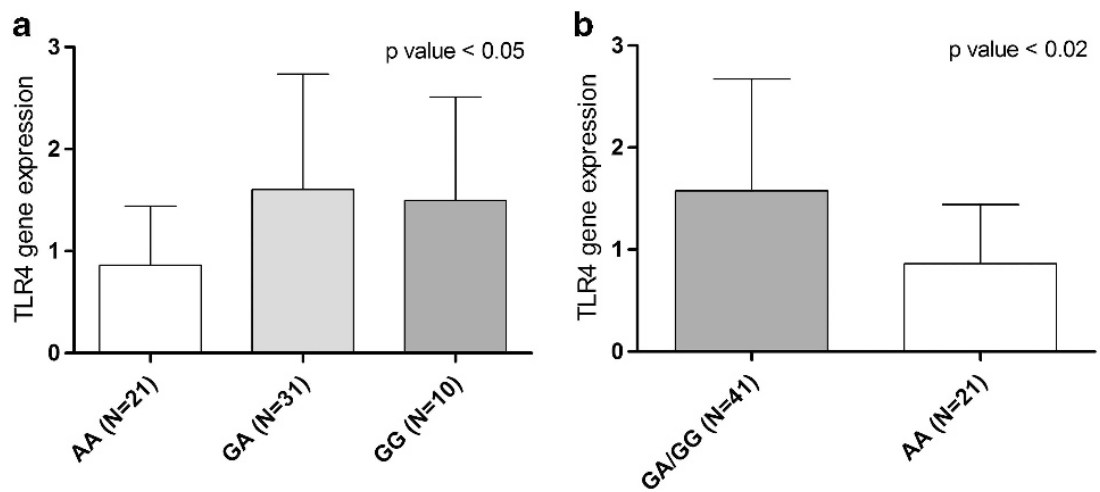

Figure 2 (a) TLR4 gene expression in relation to $-\mathbf{2 6 0 4 G}>\boldsymbol{A}$ genotypes $A A, A G$ and $G G$, and (b) in relation to individuals carrying $A A$ versus the counterpart GA/GG. Bars indicate mean values + s.d. for each group. $P$-value is indicated in the graph. 


\begin{tabular}{|l|c|c|c|c|c|c|c|c|c|c|}
\hline Nuclear extracts & + & + & + & + & + & + & + & + & + & + \\
\hline 32P probe GATA consensus & + & + & + & + & & & & & & \\
\hline NF-KB consensus (200x) & & & & + & & & & & & \\
\hline GATA consensus (200x) & & + & & & & & & & & \\
\hline 32P probe -2604A & & & & & + & + & + & & & \\
\hline 32P probe -2604G & & & & & & & & + & + & + \\
\hline -2604A (200X) & & & & & & + & & & & \\
\hline -2604G (200X) & & & & & & & & & + & \\
\hline$\alpha-$ GATA-2 & & & + & & & & + & & & + \\
\hline
\end{tabular}

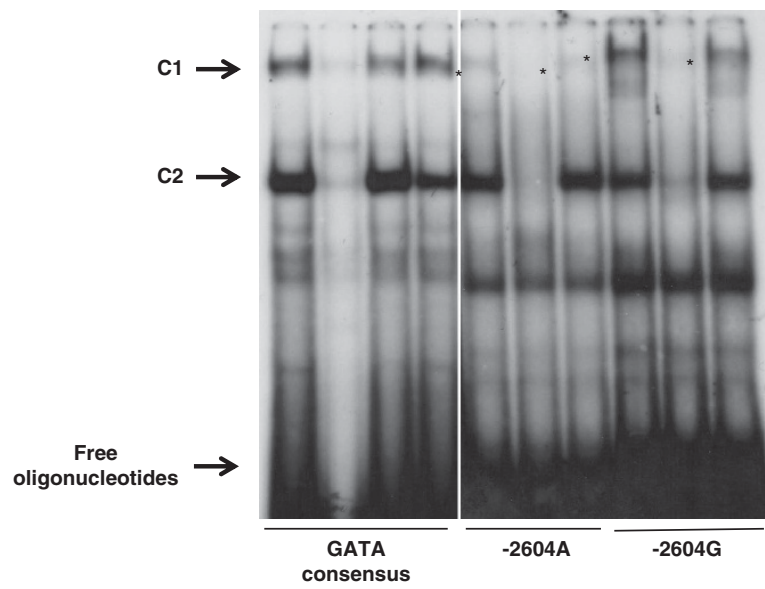

Figure 3 Electrophoretic mobility shift assay (EMSA). ${ }^{32}$ P-end-labeled oligonucelotides encompassing $-2604 \mathrm{G}>\mathrm{A}$ polymorphism or GATA consensus were incubated with nuclear extracts in the presence or absence of a 200-fold molar excess of unlabeled competitor DNA. Supershift was analyzed in the presence of antibody against GATA-2 (right panel). C1 and $\mathrm{C} 2$ and asterisks indicate protein-DNA complexes.

of the complexes with all the used probes (Figure 3), indicating that the sequence might be recognized by GATA family transcription factors other than GATA-2.

Considering that $-2604 \mathrm{~A}$ allele shows a lower level of TLR4 gene expression, and that EMSA results showed a different mobility pattern of $-2604 \mathrm{G}>\mathrm{A}$ variants, we can infer that nuclear factor/s binding to the region covering $-2604 \mathrm{G}>\mathrm{A}$ polymorphism may function as modulator(s) for TLR4 transcription, probably due to the contribution of an undetermined member of the GATA zinc-finger transcription factors. Indeed, GATA transcription factors have been demonstrated to have a crucial role in the regulation of epithelial innate immune responses. ${ }^{15-17}$

In conclusion, TLR4 is upregulated in stroke patients, indicating that TLR4 may be involved in the inflammation process leading to the ischemic event.
The presence of allele $-2604 \mathrm{~A}$ is associated with lower levels of TLR4 gene expression. This difference could be due to different transcription factors binding capacity of variants of the $-2604 \mathrm{G}>\mathrm{A}$ polymorphism.

Further case/control studies in larger populations should verify if TLR4 variant $-2604 \mathrm{~A}>\mathrm{G}$ represents a genetic marker for susceptibility to atherosclerotic plaque development and progression.

\section{CONFLICT OF INTEREST}

The authors declare no conflict of interest.

1 Lovett, J. K., Coull, A. J. \& Rothwell, P. M. Early risk of recurrence by subtype of ischemic stroke in population-based incidence studies. Neurology 62, 569-573 (2004).

2 Beutler, B. TIr4: central component of the sole mammalian LPS sensor. Curr. Opin. Immunol. 12, 20-26 (2000).

3 Dybdahl, B., Wahba, A., Lien, E., Flo, T. H., Waage, A., Qureshi, N. et al. Inflammatory response after open heart surgery. Release of heat-shock protein 70 and signaling through toll-like receptor 4 Circulation 105, 685-690 (2002).

4 Xu, X. H., Shah, P. K., Faure, E., Equils, O., Thomas, L., Fishbein, M. C. et al. Toll-like receptor- 4 is expressed by macrophages in murine and human lipid-rich atherosclerotic plaques and up-regulated by oxidized LDL. Circulation 104, 3103-3108 (2001).

5 Ohashi, K., Burkart, V., Flohe, S. \& Kolb, H. Heat shock protein 60 is a putative endogenous ligand of the toll-like receptor-4 complex. J. Immunol. 164, 558-561 (2000).

6 Methe, H., Kim, J. O., Kofler, S., Weis, M., Nabauer, M. \& Koglin, J. Expansion of circulating Toll-like receptor 4-positive monocytes in patients with acute coronary syndrome. Circulation 111, 2654-2661 (2005).

7 Edfeldt, K., Swedenborg, J., Hansson, G. K. \& Yan, Z. Q. Expression of toll-like receptors in human atherosclerotic lessons: a possible pathway for plaque activation. Circulation 105, 1158-1161 (2002)

8 Pasterkamp, G., Van Keulen, J. K. \& De Kleijn, D. P. Role of Toll-like receptor 4 in the initiation and progression of atherosclerotic disease. Eur. J. Clin. Invest. 34, 328-334 (2004)

9 Tobias, P. \& Curtiss, L. K. The immune system and atherogenesis. Paying the price for pathogen protection: toll receptors in atherogenesis. J. Lipid. Res. 46, 404-411 (2005)

10 Chen, C. W., Hwang, J. J., Tsai, C. T., Su, Y. N., Hsueh, C. H., Shen, M. J. et al. The g. $-762 \mathrm{~T}>\mathrm{C}$ polymorphism of the NPC1L1 gene is common in Chinese and contributes to a higher promoter activity and higher serum cholesterol levels. J. Hum. Genet. 54, 242-247 (2009).

11 Ferronato, S., Lira, M. G., Olivato, S., Scuro, A., Veraldi, G. F., Romanelli, M. G. et al. Upregulated expression of Toll-like receptor 4 in peripheral blood of ischaemic stroke patients correlates with cyclooxygenase 2 expression. Eur. J. Vasc. Endovasc. Surg. 41 358-363 (2011)

12 Spilker, J., Kongable, G., Barch, C., Braimah, J., Brattina, P., Daley, S. et al. Using the NIH Stroke Scale to assess stroke patients. The NINDS rt-PA Stroke Study Group. J. Neurosci. Nurs. 29, 384-392 (1997)

13 Ragnarsdóttir, B., Jönsson, K., Urbano, A., Grönberg-Hernandez, J., Lutay, N., Tammi, M. et al. Toll-like receptor 4 promoter polymorphisms: common TLR4 variants may protect against severe urinary tract infection. PLoS One 5, e10734 (2010).

14 Nakajima, T., Inoue, I., Cheng, T. \& Lalouel, J. M. Molecular cloning and functiona analysis of a factor that binds to the proximal promoter of human angiotensinogen. J. Hum. Genet. 47, 7-13 (2002).

15 Lasbury, M. E., Tang, X., Durant, P. J. \& Lee, C. H. Effect of transcription factor GATA-2 on phagocytic activity of alveolar macrophages from Pneumocystis carinii-infected hosts. Infect. Immun. 71, 4943-4952 (2003).

16 Shapira, M., Hamlin, B. J., Rong, J., Chen, K., Ronen, M. \& Tan, M. W. A conserved role for a GATA transcription factor in regulating epithelial innate immune responses. Proc. Natl Acad. Sci. USA 103, 14086-14091 (2006).

17 Kerry, S., TeKippe, M., Gaddis, N. C. \& Aballay, A. GATA transcription factor required for immunity to bacterial and fungal pathogens. PLoS One 1, e77 (2006).

Supplementary Information accompanies the paper on Journal of Human Genetics website (http://www.nature.com/jhg) 